\title{
ESTIGMA, SUBJETIVIDAD Y CIUDADANÍA SEXUAL EN MUJERES MEXICANAS BAILARINAS DE TABLE DANCE
}

\author{
Claudia Salinas Boldo \\ Instituto de Investigación y Desarrollo Educativo \\ de la Universidad Autónoma de Baja California (IIDE-UABC)
}

\section{RESUMEN}

El presente escrito es el resultado de una investigación basada en el método de la observación participante, que tuvo como objetivo el visibilizar y analizar cómo las condiciones de vida y de trabajo de mujeres bailarinas de table dance, obstaculizan e impiden el reconocimiento y el ejercicio de la ciudadanía sexual. Las mujeres bailarinas de table dance, debido a los prejuicios que rodean su actividad laboral, no se perciben a sí mismas como sujetos de derecho, susceptibles a acceder a una ciudadanía sexual plena desde la cual gocen del respeto, el reconocimiento, la protección y las condiciones de vida dignas a las que cualquier persona debería tener acceso.

\section{PALABRAS CLAVE}

Table dance, Ciudadanía sexual, Bailarinas exóticas, Derechos sexuales

\section{ABSTRACT}

The current paper is the result of a qualitative research based on the observation-participation method. Its objective was to visualize and analyze the way in which table dancers' living and working conditions hinder and obstruct the acknowledgment and exercise of their sexual citizenship. As a result of prejudice associated with their activity, table dancers do not perceive themselves as subjects of law, susceptible of full access to sexual citizenship that provides the respect, recognition, protection and a dignified life that any person should have access to. 
KEY WORDS

Table dance, Sexual citizenship, Exotic dancers, Sexual rights 
A Aimara

\section{PROBLEMATIZACIÓN}

El baile erótico, mejor conocido como table dance, es el oficio actual de muchas mujeres mexicanas. Si bien existen mujeres provenientes de otras partes del mundo, en los lugares frecuentados por parroquianos de clase media o baja, es común encontrar a mujeres migrantes nacionales, ya que es poco probable que una mujer decida bailar en el lugar del cual es originaria, pues se expone a quedar en evidencia ante los miembros de su círculo familiar o ante conocidos. Los lugares en los que bailan, generalmente, se encuentran ubicados en las afueras de la ciudad o en sectores de ésta identificados como "zonas rojas". Estos espacios abren sus puertas en horario vespertino y las cierran hasta altas horas de la madrugada. Ahí se ofrecen todo tipo de bebidas alcohólicas, acompañadas de botanas y las promociones de "cubetazos", que son cubos rellenos de cierta cantidad de cervezas, por un precio que resulta atractivo para el consumidor.

Parrini, Amuchástegui y Garibi (2014) nos dicen que las trabajadoras sexuales, buena parte de ellas migrantes nacionales, hablan de "allá", para nombrar la ciudad en la que viven, y de "acá", cuando hacen referencia a la zona que es el espacio en el que ejercen el oficio. Cuando viajan para trabajar ellas ponen distancia. Y lo hacen también cuando se arreglan y actúan su papel de bailarina. Su conducta, actitudes, atuendo, dinámicas relacionales, lenguaje, objetivos y partes del cuerpo involucradas, son todos elementos de una puesta en escena que las hace tomar distancia de la persona que son en la vida cotidiana, cuando no se encuentran en horas laborales. La parte superior del cuerpo es la que se reserva para la entrega afectiva, la "zona libre"; libre porque es posible persuadir al cliente de entrar en contacto con ella. Mientras que la parte de abajo es la que se utiliza para el intercambio comercial, es la zona que el otro usa a su antojo.

La actuación (performance), de acuerdo con Goffman (1971 [1959]), es la actividad de una persona en un momento determinado, que sirve para influir sobre las personas con las que interactúa. Cuando se establece una pauta de actuación que se repite, entonces hablamos de un papel o una rutina. En el caso de las mujeres bailarinas de table dance, su labor implica el desarrollo del papel de la "puta", esa mujer que es el opuesto de la mujer "buena" que se promueve desde la visión patriarcal. La puta como mujer que vive en el espacio de lo prohibido, en el no-lugar.

Justo y Morcillo (2008: 14) señalan que una puta:

[...] no es una mujer - y nunca puede serlosin por ello obtener otro lugar asignado que el del límite, territorio que pareciera un nolugar que sólo posibilita la demarcación de otro espacio. Como un contrasentido de los modos de construcción sociocultural de los cuerpos, lo único que queda de mujer en la puta es su sexo, como atributo marcante que materializaría la feminidad; justamente será el uso que haga de ese sexo, la práctica sexual, lo mismo que la pondrá en un lugar límite de no-mujer. Resulta sugerente pensar si la arbitrariedad del estigma, negada en sí misma, atribuido a la puta, no materializa y vela otra invención: la de la feminidad; aparecería en este caso el cuerpo siempre sexual - pero siempre impoluto- de la mujer, erigido sobre el cuerpo abyecto, siempre manchado - y a veces paradójicamente desexualizado- de la puta. 
Dicha dinámica de infravaloración de la totalidad de la persona de la mujer, a partir del oficio que le brinda sustento, es una limitante que parte de lo simbólico pero que, sin duda, tiene consecuencias en lo práctico. Muchas mujeres migran para poder dedicarse al trabajo sexual. Las mujeres se ocultan y mienten para poder cumplir con la jornada laboral. Cuando son víctimas de violencia o injusticias evitan presentarse ante las autoridades para reclamar sus derechos, y no por ausencia de necesidades o agravios, sino por la imposibilidad de pronunciarse desde el oficio que desarrollan. Pecheny (2014), quien realizó un estudio con trabajadoras sexuales, nos dice que el estigma y la discriminación que permean el oficio son la causa de que muchas de estas mujeres eviten acercarse a los servicios de salud y, si lo hacen, busquen clínicas lejanas a sus comunidades o guarden silencio en torno a su actividad laboral. Parrini, Amuchástegui y Garibi (2014) encontraron en el discurso de servidores públicos, evidencia de que para ellos es necesario establecer recordatorios de la condición humana de estas mujeres, cuando dicen que ellas también son seres humanos, a pesar de que se dediquen a la prostitución.

Las bailarinas exóticas padecen de un constante desprecio por parte de una sociedad que las mira a través del estereotipo de la mujerobjeto, invisibilizando las condiciones sociales y económicas que las orillaron a dedicarse al trabajo sexual. Muestra clara de esto último son los mitos que giran en torno al oficio, como el de que es un trabajo "fácil" y de una vida "alegre" (Jeffreys, 2011 y Lagarde, 2005).
Desde el tubo, objeto alrededor del cual se gira bailando, estas mujeres comercian con el erotismo, con el objetivo de generar un recurso económico. Se trata de mujeres trabajadoras que son madres, hijas y compañeras. Mujeres a quienes se define desde lo erótico pero que, irónicamente, viven ajenas al reconocimiento y ejercicio de sus derechos sexuales, como lo es el derecho a la salud, misma que no se protege en un espacio laboral en el que está siempre presente la invitación a alguna clase de interacción sexual remunerada. Jeffreys (2011), quien nos habla del trabajo sexual en Estados Unidos, dice que, si bien el striptease por definición no involucra contacto físico, muchas veces las mujeres se ven obligadas a negociar algún tipo de intercambio sexual no-coital en el espacio de los "privados" — en los cuales se realiza el lap dance ${ }^{1}$ que el cliente paga aparte. Algo similar ocurre en México, en donde los clientes no siempre se conforman con mirar a la chica en un baile privado sin tocarla o solicitar tocamientos de parte de ella.

Cabe destacar que a diferencia de la literatura en torno a la prostitución o el trabajo sexual, lo que se ha escrito sobre la temática del table dance no es abundante. Sin embargo, es importante hacer visible el hecho de que, como en el caso de la prostitución, en el marco del table dance también puede haber en ocasiones coito, así como intercambios no coitales, quedando en riesgo la salud de quienes participan en dichos intercambios.

1 Lap dance hace referencia al "baile de regazo", que es el tipo de baile que la bailarina realiza en el espacio de los privados, o en la mesa del cliente. El baile de regazo consiste en moverse de forma erótica sobre las piernas del cliente, quien permanece sentado todo el tiempo observando. 
En el presente trabajo se considera al baile erótico como una forma de trabajo sexual, ya que se hace hincapié en el hecho de que se comercia con el erotismo y la excitación sexual.

Olvera (2006: 322) se refiere a la definición hecha por Delacoste y Alexander (1998) del trabajo sexual de la siguiente manera:

[...] una actividad que forma parte de la industria del sexo, en la que la fuerza del trabajo es el cuerpo y lo que se vende es un servicio. Esto no siempre implica una relación sexual o contacto directo con el cliente, ya que las personas que laboran en el sex work pueden ser desde modelos desnudas de revistas, actrices y actores de pornografía, call girls, escorts o acompañantes, strippers, bailarinas eróticas o exóticas, masajistas y personas que trabajan en las estéticas y salas de masaje que ofrecen servicios sexuales, hasta las mujeres que se prostituyen en la calle o en prostíbulos.

De esta manera, podemos entender el baile erótico o table dance como una de las tantas actividades que se catalogan dentro del rubro del trabajo sexual, ya que si bien es una actividad cuya esencia no incluye ningún tipo de intercambio físico con el cliente, sí es una actividad en la que se involucra el cuerpo con una finalidad erótica (Villa, 2010).

A propósito de los términos empleados, Jeffreys (2011) se pronuncia en contra de llamar "trabajo sexual" a la actividad de estas mujeres, así como de llamar "clientes" a quienes pagan por sus servicios, ya que considera que ésta es una forma de normalizar esta actividad, invisibilizando así el hecho de que el sistema de la prostitución - como ella decide denominarlo- es una industria capitalista que explota el cuerpo de las mujeres para el beneficio sexual y económico de los hombres. Es por esta razón que ella prefiere referirse a estas mujeres como "prostituidas". Yo he decidido no llamarlas "prostitutas" pues este término es utilizado para aquellas mujeres que, de forma directa y explícita, venden coitos. Y tampoco "mujeres prostituidas" porque es un término que hace referencia a la mujer como víctima. Si bien estoy de acuerdo en que constituyen el elemento oprimido y explotado de esta cadena comercial, victimizarlas no es la propuesta más acertada que podemos ofrecer. He decidido, entonces, hacer uso del término "trabajadora sexual", pues considero que la actividad que realizan entra dentro de la definición de trabajo sexual anteriormente ofrecida y porque, para ellas, constituye su fuente de ingresos.

Cabe destacar que han existido posturas abolicionistas contra el trabajo sexual, pero éstas se instalan en un desconocimiento de la capacidad que tenemos todos los individuos para decidir por nosotros mismos. Consideran a las trabajadoras sexuales como víctimas pasivas y esclavizadas a las cuales lo mejor que podría pasarles es ver desaparecer su fuente de trabajo. En el presente artículo se apoya la postura de aceptar la existencia del trabajo sexual voluntario, regulado y desarrollado en condiciones dignas para aquellas personas que lo ejercen. Esto implicaría la existencia de contratos escritos celebrados entre personas legalmente adultas, en los cuales se contemplen obligaciones y derechos tanto para quien emplea como para aquel que es empleado. De esta manera las mujeres bailarinas percibirían un salario justo, prestaciones de ley como son las vacaciones, la jubilación y 
el servicio médico, y la posibilidad de solicitar protección legal a las instancias públicas en caso de necesitarla.

Barrero Díaz (2004) realizó una investigación con bailarinas exóticas migrantes de Colombia en Canadá, y refiere el hecho de que estas mujeres trabajan en un marco de invisibilización de sus derechos laborales. Con promesas y mentiras son “enganchadas” para bailar en Canadá en condiciones de explotación, injusticia y carencia. No se cumplen las condiciones mínimas de respeto a sus derechos como trabajadoras. Los acuerdos son arbitrarios y tomados unilateralmente. No existen contratos escritos ni instancias que las protejan. Asimismo, destaca el hecho de la migración como circunstancia significativa en la vida de estas mujeres, quienes dejan atrás a sus familias y redes de apoyo. Esto las coloca en posición vulnerable con respecto a sus patrones ya que llegan a depender de ellos para, simplemente, sobrevivir en un país extranjero del cual conocen poco.

Por otro lado, Briz y Garaizabal (2007) estudian la situación de mujeres extranjeras que llegan solas a España para ejercer como trabajadoras sexuales de forma voluntaria, sin que medie la coerción por parte de ninguna persona u organización. De aquí se rescata el hecho de que no todo en el mundo del trabajo sexual es trata. Es verdad que la trata existe y constituye un problema alarmante que requiere de una solución urgente, como es verdad que muchas mujeres acuden voluntaria y "libremente" a estos espacios.

Sostengo que esta "libertad" es un proceso relativo — razón por la cual la entrecomilloporque, en la mayoría de los casos, esta decisión se toma más por la ausencia de otras opciones, y no tanto porque las mujeres encuentren en ella la vía ideal para el logro de un bienestar y realización personales, más allá de lo económico (Justo y Morcillo, 2008; Lagarde, 2005; Parrini, Amuchástegui y Garibi, 2014).

En México las cosas no son demasiado distintas. Basada en una investigación realizada en Guadalajara con bailarinas exóticas, Olvera (2006) concluye que este es un trabajo totalmente informal en el cual no existen garantías ni prestaciones de ninguna clase para las mujeres que trabajan ahí. Se trata, dice, de mujeres obligadas por su situación económica, que se ven forzadas a aceptar condiciones de trabajo abusivas e inhumanas.

Existen muchas mujeres que voluntariamente se suman a las filas de la prostitución, del baile erótico o a ambas cosas, pues no les es posible acceder a otro tipo de empleo que les permita solventar sus necesidades básicas. Y si bien esta actividad les reporta mayores ingresos que cualquier otra en la que, dado su nivel educativo, pudieran insertarse, es importante destacar el hecho de que se da en condiciones arbitrarias. Esto aunado al estigma con el que deben lidiar de manera constante.

\section{PROCEDIMIENTO}

La presente investigación se encuentra metodológicamente enmarcada en la antropología feminista, la cual, de acuerdo con Castañeda, centra su atención en "todas las expresiones de las mujeres en términos de ser y hacer que, aún hoy, son desconocidas, ignoradas, silenciadas u omitidas" (Castañeda, 2006: 41) y más adelante en el texto, continúa hablando de la posición metodológica 
feminista como un quehacer cuyo objetivo es el de "aportar conocimientos comprometidos, situados, críticos y propositivos vinculados con la justicia, la igualdad, la equidad, el desarrollo y la democracia" (Castañeda, 2006: 45)

Todo lo anterior se realizó sin perder de vista la objetividad científica, pero una objetividad sostenida desde una posición distinta a la patriarcal. Haraway (1988) nos habla de esto cuando aboga por la construcción de una objetividad científica que enfatice la visión de las mujeres, la vivencia corporeizada que proviene de una mirada mediada por los significados, la experiencia y las posiciones particulares. Una objetividad que provenga del conocimiento localizado y que busque la deconstrucción, las subjetividades, las conexiones, la construcción apasionada, la transformación de sistemas de conocimiento y rescate la forma de ver las cosas. Todo esto sin privilegiar la posición de los subyugados, pues esta visión no es promesa de mayor objetividad. La posición subyugada no es inocente. Es una forma de mirar, criticable y específica como cualquier otra.

Desde el quehacer científico feminista, advierte Scott (1992), no sólo deberemos ocuparnos de la tarea de hablar de las diferencias entre hombres y mujeres, sino también de visibilizar la manera en la que esta forma de pensamiento binario funciona para reprimir las diferencias al interior de cada género. Resulta importante, pues, el destacar la existencia de experiencias individuales. No hablar de "la mujer" sino de vivencias de mujeres, porque "al subsumir a las mujeres dentro de una identidad 'humana' general, perdemos la especificidad de la diversidad femenina y las experiencias de las mujeres" (Scott, 1992: 101).

Así, la reflexión feminista se centra en la paradoja de la mujer como elemento de ficción estática. Es decir, cuestiona la idea de "la mujer" cómo concepto que nos abarque a todas. Es por esto que se busca construir el feminismo como un espacio en el que se trabaje desde las diferencias que emanan de las diversas posiciones, subjetividades e identidades. Un lugar en el que tengan cabida todas las mujeres. Un espacio plural y diverso (De Lauretis, 1993).

La observación participante, que es definida por Kawulich (2005: 30) como el método que requiere de un involucramiento por parte de quien investiga "que le permita observar a los miembros culturales en sus vidas diarias y participar en sus actividades para facilitar una mejor comprensión de esos comportamientos y actividades", fue el método que se utilizó en esta investigación, ya que yo misma trabajé como bailarina erótica en dos establecimientos de table dance ubicados en la llamada "zona rosa" de la Ciudad de México; dos más ubicados en la zona centro y uno en el Estado de México.

Dicha metodología, aplicada al tema del trabajo sexual, no es común en México pues las investigadoras que han trabajado el tema han obtenido sus datos de entrevistas a profundidad hechas a bailarinas y, en el caso de Olvera (2006), parte de sus datos los obtuvo solicitando empleo como bailarina, pero sin llegar a presentarse en el escenario. Yo bailé en los escenarios, conviví con los clientes, "fiché" e hice "privados". Esto me dio 
la oportunidad de estar en los camerinos, platicar informal y espontáneamente con las chicas —en calidad de compañera de trabajo - y sentir en carne propia el trato que estas mujeres reciben por parte de meseros, boleteras, patrones y capitanes de meseros, lo cual me brindó una mirada más amplia y cercana de esta problemática.

No se llevaron a cabo entrevistas, ya que eso hubiera implicado mi identificación como investigadora, junto con la búsqueda de una firma de consentimiento informado y la audiograbación de lo dicho por parte de ellas, lo cual no formó parte de la metodología planeada.

El trabajo de campo se llevó a cabo en un lapso de ocho meses en 2012, antes de que iniciara el cierre masivo de estos establecimientos en nombre de la lucha en contra de la trata de personas.

En mi caso, la decisión de convertirme en trabajadora sexual no fue algo motivado por la necesidad económica, ni mucho menos fue producto de alguna acción coercitiva ejercida en contra de mi persona. La decisión fue motivada por una inquietud personal. El interés científico se despertaría sobre la marcha, dando como resultado este trabajo que está basado en un diario de campo que se nutría con cada nueva jornada de trabajo, y que cuenta con una condicionante que no me es posible dejar de mencionar: el sueldo obtenido de este trabajo nunca constituyó mi principal sustento y tampoco significó una solución desesperada ante circunstancias límite.

A propósito de lo anterior, Castañeda (2012) nos dice que es importante romper el ideal romántico de la investigación feminista que insinúa equivalencia en las relaciones intersubjetivas entre las mujeres por el simple hecho de ser congéneres.
Esto no es así, ya que existen diferencias entre las mismas mujeres, no sólo las diferencias evidentes sino aquellas que se desprenden de la clase, los recursos y la posición. La autora nos dice que la posición de quien investiga, será siempre ventajosa con respecto a aquellas que son investigadas.

Los lugares de trabajo fueron elegidos con base en los siguientes criterios: a) que estuvieran ubicados en zonas muy transitadas y/o cercanas a estaciones de metro, paradas de autobuses o sitios de taxis y b) que en ellos fuera aceptada — se dio el caso de un sitio de mayor plusvalía en el que no fui aceptada por tener un tatuaje y cicatrices visibles en el abdomen.

Desde la observación participante y en mi calidad de antropóloga y trabajadora sexual, realicé labor científica en estos lugares, lo cual me permitió observar los riesgos a la salud sexual generados por el desarrollo del baile erótico como opción de trabajo sexual; los procesos subjetivos que entorpecen el acceso a la salud sexual; los procesos subjetivos que permean la autoidentificación de las bailarinas como sujetos de derechos sexuales y laborales, así como explorar el papel del estigma introyectado, proveniente de imaginarios heteronormativos, como elemento inhibidor del proceso de apropiación de ciudadanía sexual en estas mujeres.

\section{RESULTADOS}

De mi propia experiencia como bailarina en la Ciudad de México y el Estado de México puedo hablar del hecho de que existen lugares en los cuales la condición para cobrar el sueldo del día - el cual fluctúa entre los 300 y 900 pesos, dependiendo de la apariencia física de la bailarina- es la de 
"hacer" tres copas. Es decir, lograr que durante la jornada laboral los clientes nos inviten tres copas, las cuales tienen un sobreprecio — parte del cual constituye una ganancia para la bailarina. A esto se le conoce como "tabulador". Solamente teníamos derecho a descansar un día de la semana y por cada jornada que no nos presentáramos a trabajar teníamos que pagarlo con un día de trabajo en el cual no teníamos derecho a cobrar el sueldo del día. Es decir, dependíamos de los "privados" y de las copas. En el table dance del Estado de México no había "tabulador" y esto el patrón lo mencionaba como una ventaja laboral, junto con el hecho de que teníamos derecho a una cena de comida casera que se elaboraba ahí mismo, sin costo alguno, cosa que no he sabido que se ofrezca en ningún otro lugar.

Tal como relata Olvera (2006), todo empieza con una entrevista en la cual se nos explica a las bailarinas los requisitos y obligaciones laborales. Todo se da en condiciones de absoluta informalidad, sin documentos de por medio. Al empleador quien generalmente es el capitán de meseros - no le interesa conocer el nombre real de la chica. A mi únicamente me preguntó mi "nombre artístico" y me pidió que al trabajo siempre trajera mi credencial del IFE para comprobar que soy mayor de edad "por si acaso", refiriéndose con esto a la posibilidad de redadas dentro del local. En el Estado de México, el dueño me pidió una copia de mi credencial del IFE, para que, en caso de que las autoridades irrumpieran sin previo aviso, pudiera comprobar que todas sus bailarinas éramos mayores de edad.

El nombre que elegí fue el de "Aimara" inspirado en el nombre de la etnia sudamericana de los Aymara-, seudónimo que, curiosamente, los
DJ's pronunciaron bien en raras ocasiones, pues yo siempre era convocada a subir al escenario como "Amaira" o "Amaya", entre otros.

Se deben de cumplir ocho horas de trabajo y en ocasiones más, cuando no llegan suficientes chicas para cubrir el siguiente turno. Generalmente, cuando se hacen horas extra, es la bailarina la que permanece en el lugar voluntariamente. Esto en caso de que haya conseguido un buen cliente y con ello la posibilidad de hacer más copas y privados. En el primer lugar en el que trabajé, ubicado en la zona rosa, me pedían que entrara una hora antes de que el lugar abriera. El tiempo que una está en el camerino no se toma en cuenta. La jornada laboral empieza a correr a partir de que la bailarina se presenta en el "salón”. En algunos lugares es posible elegir el turno de trabajo: vespertino o matutino. Pero no en todos.

Cabe mencionar que el sueldo del resto de los empleados del table dance sale directamente del trabajo de la bailarina, por lo cual ésta se encuentra constantemente presionada para tener clientes y venderles la mayor cantidad posible de copas y privados. Los meseros no tienen sueldo fijo, su sueldo lo constituye el 15 por ciento del total que se consuma durante su turno en las mesas que le son asignadas. Los meseros suelen llevar a las bailarinas a las mesas, las presentan con los clientes y las dejan ahí unos minutos, esperando que la chica consiga que éstos le inviten una copa. De no ser así, el mesero retira a la chica de la mesa, o son las mismas chicas las que deciden levantarse y probar suerte con otros clientes.

En caso de que la chica consiga quedarse en la mesa, los meseros las conminan, por medio 
de miradas o señales, para que consuma su copa rápidamente, de tal manera que el cliente tenga que invitarle otra. Asimismo, las boleteras se pasean por las mesas en las que hay bailarinas sentadas para motivar al cliente a pagarse un privado con ellas.

Generalmente, del sueldo diario de la bailarina se descuenta una cantidad fija - alrededor de 50 pesos - para pagarle al DJ y a la "mami".

Por un lado, el DJ se encarga de poner la música que bailan las chicas. Cada bailarina tiene "sus" canciones. Ellas deciden qué es lo que desean bailar y le informan al DJ, el cual protege la exclusividad de dicha canción, de tal forma que ninguna otra chica baile las mismas canciones que ya haya pedido alguna otra. Únicamente en caso de que la "titular" de la canción falte, el DJ puede ponerle la canción a alguna otra chica que la solicite.

Por el otro lado, la "mami" es una figura indispensable en cualquier table dance. Ella permanece ahí desde que abre el establecimiento hasta que cierra. Por lo general, se trata de una mujer de mediana edad o joven — pero alejada del estereotipo occidental de belleza que regularmente se exige en estos lugares - que se ubica en el camerino y cuya labor es la de auxiliar a las bailarinas en labores diversas. Las "mamis" siempre tienen a la mano maquillaje, crema corporal, zapatos, ropa de trabajo, peines, toallas sanitarias, medicina y papel de baño, entre otras cosas que pudieran necesitarse. Asimismo, está disponible para conseguirles comida y golosinas a las chicas, cuidar de sus pertenencias, ser su confidente, actuar como conciliadora en los pleitos y vigilar que se cumplan las reglas de la casa. De vez en cuando se recibe en los camerinos la visita de otras "mamis" que llevan ropa, zapatos y perfumes para venderles en abonos a las chicas. Las “mamis" son, también, las encargadas de llevar y traer chismes de otros establecimientos de table dance a los que acuden a ofrecer su mercancía. En alguna ocasión me tocó conocer a una "mami” que elaboraba ropa de trabajo al gusto de la bailarina. Esta mujer ofrecía disfraces de enfermera, caperucita roja, blanca nieves, diabla, y Alicia - la del país de las maravillas_-, entre otros. Los trajes tenían un precio determinado, pero si la bailarina deseaba que ese diseño fuera exclusivo debía de pagar un costo extra, a cambio del cual la "mami" se comprometía a no reproducir ese modelo para ninguna otra bailarina, de ese lugar o de cualquier otro.

Una de las reglas de los table dance es la de no hacer uso del teléfono celular dentro del salón, pues esto ocasiona que las chicas se distraigan con sus teléfonos en vez de buscar activamente clientes. Esta regla es ampliamente ignorada por las bailarinas, quienes se las ingenian para tener siempre a la mano sus teléfonos. Sin embargo, deben de ser discretas pues se arriesgan a ser sancionadas.

En alguna ocasión una de las chicas me platicó que la castigaron por traer el teléfono celular escondido en una de sus botas. A la hora de la salida el patrón la mandó llamar a su oficina y una vez ahí le mostró el video, tomado por la cámara de seguridad, en el cual se le veía sacando el teléfono de su bota. Ese día la chica no recibió sueldo. En algunos lugares, la "mami” es la encargada de hacer cumplir esta regla, pues impide que las chicas abandonen el camerino con sus teléfonos a la mano y también que permanezcan mucho tiempo ahí arreglándose, comiendo, platicando o usando el sanitario. La “mami” es, pues, quien acompaña a las 
chicas y quien, al mismo tiempo, se convierte en los ojos del patrón dentro de ese espacio, supuestamente privado y libre de control.

En México se desconoce el número exacto de mujeres dedicadas al table dance, pero es posible identificar que muchas de ellas son pobres y migrantes. Su rango de edad es amplio, va de los 17 a los 45 años. La mayoría de ellas se inició en la maternidad muy joven y se encuentra viviendo en pareja; es de clase baja, con poca escolaridad y migrante nacional, cuya familia ignora o finge ignorar su oficio. La presencia de adicciones a la droga o el alcohol es común, así como la violencia en el círculo familiar.

Si bien es posible hablar de este perfil promedio, existen algunas diferencias entre las mujeres bailarinas de table dance que resulta importante mencionar. Uno de tantos días me encontré en el salón a una chica nueva - dato que adiviné por las zapatillas convencionales que traía. Hija de una familia de clase media alta, deseaba estudiar una carrera universitaria que su padre no estaba dispuesto a pagar "porque soy mujer y me voy a casar algún día”. Y trabajando de medio tiempo, con la preparatoria terminada como única escolaridad, no iba a poder pagar las colegiaturas de la universidad — privada — a la que acababa de ingresar.

Y así como esta historia hay una larga lista: el par de chicas, estudiantes universitarias, que durante el turno vespertino - caracterizado por la baja afluencia de clientes - se la pasaban estudiando sus apuntes - lámpara en mano- en la mesa más alejada del salón, mientras esperaban su turno para bailar; la chica que se gastaba todo su sueldo en noches de antro y maquillaje "de marca"; la madre de dos hijos que estaba esperando terminar su licenciatura para dedicarse a su profesión, a sabiendas de que, como abogada, iba a ganar menos que lo que ganaba bailando-, para no volver a desvelarse nunca más; la que se pagó la cirugía de aumento mamario; la que era chantajeada por el novio, quien había descubierto que no era mesera del turno nocturno, después de haberla seguido hasta su sitio de trabajo una noche; la que considera que no le está siendo infiel a su novio - quien ignora su oficio- al tener relaciones sexuales con los clientes, "porque eso es trabajo"; la que tiene una familia que lo sabe todo y lo tolera porque "de ahí comen"; las que saliendo del trabajo se iban a la fiesta y regresaban al trabajo sin haber dormido, bajo los efectos de alguna droga ilegal; la que dejó el trabajo motivada por la promesa de manutención de un hombre y regresó después porque él no pudo ofrecerle lo mismo que ella ganaba bailando; la que empezó como edecán, repartiendo volantes en la entrada del "teibol" y terminó bailando $-\mathrm{y}$ ganando mucho más-; la que estaba tentada a creer en las declaraciones de amor de un cliente que insistía en llevarla al cine, fuera de su horario de trabajo; la que estaba esperando a que el novio se reportara y le mandara dinero para reunirse con él en el "otro lado"; y la que se ofreció a decirme cómo sacar más dinero sin necesidad de "meter cuerpo", de dejarse tocar.

Son mujeres en un país en donde la violencia de género y los valores patriarcales aún continúan vigentes. Si a esto le sumamos el aislamiento, que es condición de vida propia de quien migra, y el desarrollo de un oficio fuertemente estigmatizado, 
nos encontramos con una suma de elementos que da como resultado condiciones de vida que mantienen a las mujeres bailarinas en un estado de marginación constante.

La exclusión de estas mujeres se construye desde los imaginarios que las rodean, que son aquellos que giran en torno a la figura de la “puta”. Y la puta, en nuestra cultura, es la mujer que desarrolla cualquier tipo de trabajo sexual, independientemente de que ocurra el intercambio coital o de que éste se encuentre ausente durante el desarrollo de la actividad laboral.

Lagarde nos dice que "ideológicamente se identifica puta con prostituta, pero putas son, además, las amantes, las queridas, las edecanes, las modelos, las artistas, las vedettes, las exóticas, las encueratrices" (Lagarde, 2005: 543). Las putas en la fantasía social son hipersexuales, salvajes, independientes, malas, indecentes, promiscuas, viciosas, descaradas, impuras, obreras, ligadas a lo público, no madres y migrantes (Villa, 2010).

Las bailarinas de table dance califican dentro del imaginario de "la puta" pues trabajan con su sexualidad, desde el erotismo. Se desnudan ante hombres desconocidos y reciben un pago por algo que, desde la heteronormatividad, las mujeres deberíamos entregar de forma gratuita, en nombre del amor y con compromiso socialmente reconocido de por medio.

Al respecto, Palencia (2004) nos dice que la estigmatización provoca aislamiento, además de que se utiliza para justificar los malos tratos de los cuales son víctimas estas mujeres. Esta autora señala que existe una especie de esencialismo, derivado del estigma, que es la causante de que estas mujeres no tengan movilidad laboral. Sin embargo, yo considero que la permanencia en esta actividad está más relacionada con el tema de lo económico que con el estigma, ya que, como bien mencionan Loaiza, Moreno y Zuluaga (2007), el trabajo sexual es percibido - y lo es, de hechocomo un oficio mucho más rentable que cualquier otro. Tomando en cuenta el hecho de que quienes lo realizan son mujeres cuyo nivel académico no les permite acceder a empleos regulares y mejor remunerados. Es por esto que las mujeres que se dedican a este oficio, como las mismas autoras indican, deciden permanecer en él, aunque esto signifique vivir en paralelo, mintiendo todo el tiempo a la gente cercana a ellas, para no ser descubiertas, y exponiéndose a los peligros que se derivan de su actividad.

Una de las preguntas que me hacían durante las entrevistas de contratación era: “¿haces 'salidas”?” Esto quiere decir que si estoy dispuesta a tener relaciones sexuales con los clientes, en caso de que ellos hagan ofertas.

Cuando las "salidas" ocurren, a "la casa" se le tiene que pagar entre 700 y 2,000 pesos mexicanos para que la chica se retire del salón —a algún hotel cercano o a habitaciones especialmente dispuestas al interior de los table dance- a fin de sostener encuentros sexuales con el cliente, quien debe cubrir la cuota que la chica decida cobrar por sus servicios. Estas cuotas, en los lugares donde yo trabajé, van desde los 500 hasta los 2,500 pesos mexicanos. En el table dance del Estado de México había un motel ubicado justo a un lado del establecimiento, de tal manera que cuando alguna chica era requerida para una "salida", uno de los elementos de seguridad 
del lugar la acompañaba al hotel y la iba a buscar después, para asegurarse de que no tuviera ningún tipo de problema. Asimismo, el dueño siempre estaba pendiente, por medio de llamadas telefónicas, de que los encuentros se llevaran a cabo sin percances y la chica estuviera segura en todo momento. Pero eso sí, cuando una chica hace una "salida", ya no se le paga el sueldo del día, por eso se le sugiere que le cobre lo más posible al cliente, considerando el hecho de que no recibirá sueldo esa noche.

Como bien dice Olvera (2006), el contacto sexual entre cliente y bailarina puede ocurrir, pues al abrigo de los vacíos legales se ofrecen y consumen servicios sexuales que benefician a los centros nocturnos, estéticas y casas de masajes y brindan beneficios económicos adicionales e inmediatos a las mujeres que aceptan prostituirse, aunque esto signifique exponer su cuerpo a infecciones de transmisión sexual, agresiones y embarazos no deseados que la empresa que las contrata no les va a cubrir e indemnizar en caso de que efectivamente sucedan. El table dance es parte de la industria del sexo y para bien de quienes laboran en los centros nocturnos, es un trabajo que debe regularse, pero no como una forma de perseguir a las bailarinas y aumentar la explotación que ya padecen con el pretexto de "proteger" a los clientes, sino con el ánimo de visibilizar los riesgos que conlleva este trabajo y atender a las necesidades de quienes lo practican.

Es importante mencionar que, en muchos casos, no existe ninguna clase de dispositivos de seguridad encaminados a garantizar la integridad de la chica que hace salidas con clientes que desean llevarlas a algún hotel en específico o a su domicilio. La bailarina que sale se expone entonces a llegar a un lugar desconocido en donde no sabe qué es lo que va a encontrar, quedando así completamente expuesta a toda clase de abusos que pueden ir desde violaciones, pasando por golpes, hasta llegar al asesinato.

Si bien en sus inicios el table dance no fue una actividad ligada al fantasma de la prostitución, es una realidad que hoy por hoy los "teibols" son espacios en los cuales es posible encontrar ofertas de sexo comercial por parte de algunas bailarinas. López (2002) atribuye esto al factor económico, por un lado, y a la inequidad de género, por el otro. Él considera que la cosificación sexual de las mujeres y la escasez de oportunidades laborales y académicas - en especial para las mujeres - prepararon el terreno para que, rápidamente, el table dance en nuestro país se asociara a la prestación de servicios coitales por parte de las bailarinas. Y a esto le añade el hecho de que, siempre, lo clandestino y prohibido resultará especialmente atractivo a una sociedad que vive sumergida en la doble moral.

En dos de los lugares en los cuales bailé, había un espacio ubicado en un segundo piso, especialmente dispuesto para los encuentros sexuales. Estos espacios, como me explicó uno de los meseros, no pueden tener el aspecto de cuartos de hotel, pues se supone que son para bailes o "eventos" privados. Aunque todos saben que esas habitaciones se destinan para las "salidas" de las chicas.

Incluso aquellas bailarinas que no acceden a tener "salidas" se encuentran expuestas a riesgos, ya que muchas veces ofrecen a los clientes cosas tales como sexo oral y el dejarse tocar como un "plus" 
que sirve para convencerlos de pagar por un privado con ellas. Los mismos clientes me hablaron acerca de esto cuando se tocaba el tema de los privados. Me preguntaban: “¿y tú qué te dejas hacer?”, después de lo cual me contaban que preferían preguntar antes para no "tirar el dinero" con alguna chica "que no se deja hacer nada" durante el privado, refiriendo el caso de otras que si se dejaban tocar y besar, que hacían sexo oral e incluso permitían penetraciones rápidas en ese espacio en el cual, se supone, únicamente se hacen "privados".

Es muy común, por ejemplo, que al estar sentadas en la mesa con los clientes, las bailarinas permitan tocamientos a sus genitales, lo cual las expone a contraer infecciones que, si bien es poco probable que sean mortales, si afectarán su salud sexual y reproductiva en caso de presentarse.

En la base de la invisibilización de los derechos laborales de las bailarinas se encuentra sin duda la estigmatización. Sus denuncias frente a la autoridad — si es que estas se llevan a cabodifícilmente serán tomadas en serio debido a su oficio, lo cual las deja en una situación de franca vulnerabilidad frente a los abusos de sus empleadores y clientes (Palencia, 2004).

El table dance no es reconocido como trabajo porque es una actividad ligada a la prostitución, la cual a su vez no es reconocida como trabajo por el estigma, la desvalorización y la esencialización que conlleva. La invisibilización de los derechos humanos y laborales de estas mujeres se ve como un castigo que deben de pagar por ser lo opuesto a la "buena mujer" (Pachajoa y Figueroa, 2008). Es por esto que, como una clara expresión de castigo patriarcal, desde lo social, lo académico y lo político, se les abandona e ignora.

La doble moral patriarcal imperante en nuestra cultura, nos divide a las mujeres en putas y decentes. Las putas son el mal, el pecado. Esta concepción está en la base de la violencia simbólica que se dirige todo el tiempo a las mujeres eróticas (Lamas, 1993; Pachajoa y Figueroa, 2008). Estas mujeres son consideradas entonces como hipersexuales, salvajes, independientes, malas, indecentes, promiscuas, viciosas, descaradas, impuras, ligadas a lo público y proletarias. Igualmente, debido a su papel como mujeres trabajadoras sexuales, se invisibiliza su rol como madres y esposas - que muchas de ellas lo son- pues su actividad laboral no es compatible con el estereotipo maternal-conyugal dominante (Villa, 2010).

Ser mujer erótica no es un trabajo como cualquier otro. Por su antagonismo con la sexualidad socialmente aceptada, y porque la sexualidad es esencia de la condición de mujer dentro del patriarcado, ser teibolera es un modo de vida total, simbólicamente hablando. Ellas son pensadas como malas pues aunque todas las mujeres tengan vida sexual solo las mujeres que comercian con su cuerpo desnudo, la encarnan y la simbolizan (Lagarde, 2005; Pachajoa y Figueroa, 2008).

Este rechazo también se introyecta, dando como resultado una especie de estigma secundario que a mí me tocó conocer durante mis días de bailarina erótica.

Es raro que tres o más bailarinas coincidan en una sola mesa ya que, en general, no se permite a las chicas que socialicen mucho entre ellas, pues esto las distrae de la búsqueda de clientes. Pero, en una afortunada ocasión, tuve la oportunidad de 
participar de una improvisada reunión de cinco chicas - incluyéndome - en una de las mesas del lugar. Yo era la recién llegada y la conversación se inició con una pregunta que fue dirigida a mí, con la intención de saber si mi presencia en ese lugar respondía a una fuerte necesidad económica o a un auténtico gusto por el desarrollo del oficio: " $¿$ a ti te gusta hacer esto?" Acto seguido, se desató una conversación en torno al hecho de que "las verdaderas putas" son aquellas que disfrutan del trabajo, mientras que las mujeres decentes eran aquellas que trabajaban de putas porque la pobreza no les había dejado otro camino. Yo les pedí que me explicaran un poco mejor esto, a lo que ellas respondieron ejemplificando el caso de una de las chicas más populares - no presente en la mesa - que "evidentemente" disfrutaba de su trabajo, pues se le notaba muy segura, desenvuelta $\mathrm{y}$ alegre en todo momento. Cosa distinta a quienes lo hacían "por necesidad", ya que la vergüenza muchas veces les impedía mirar a los clientes durante el baile o incluso animarse a acercarse a las mesas para ofrecer su compañía. Como bien me dijo una de ellas: "yo cuando bailo miro a la pared o al piso, porque me da mucha pena hacerlo, pero ni modo."

Aunado al papel que ellas interpretan todos los días, está la dramatización de ese papel (Goffman, 1971 [1959]). No basta con llevar a cabo una actividad, hay que llevar la actuación un poco más allá, ponerle acento, hacerla parecer que viene desde adentro, que se está convencido de lo que se hace. En el caso de aquella mujer calificada por las otras bailarinas como la que "de veras" es puta — la dramatización del papel —la actitud de estar siempre alegre y aparentemente cómoda en su propia piel - redundaba en un nivel de popularidad y ganancias que las otras no tenían. Vidal (2002) y López (2008) nos dicen que si bien las mujeres dedicadas al trabajo sexual consideran éste un trabajo como cualquier otro, están conscientes del rechazo que produce en la sociedad, y responden a la estigmatización reafirmándose en su papel de esposas, estudiantes, hijas y madres —esto último especialmente-, pues es la forma en la cual imponen distancia entre su oficio y su identidad como mujeres, con el objetivo de salvaguardar su propio autoconcepto y autoestima. Esto se complementa con las mentiras constantes a las que deben recurrir para no ser descubiertas y con una relación siempre ambivalente con sus compañeras de trabajo, ya que estas relaciones están marcadas por la desconfianza y la competencia. López define bien este fenómeno cuando nos dice que "la identidad social se construye con base en la valoración social que se concede a la propia ocupación" (López, 2008: 273), es decir que, cuando se da el estigma, la identidad personal y la social se dividen pues de esta forma se protege la persona a sí misma.

Goffman (1970) hace referencia al estigma de los desacreditables, es decir, aquellas personas cuya condición estigmatizable no se conoce abiertamente, como sería el caso de las mujeres bailarinas, quienes invierten considerables esfuerzos en mantener el secreto de su oficio ante las personas cercanas.

La mujer erótica puede ser vista como víctima pasiva de las circunstancias o culpable de encarnar una lascivia que atenta contra los 
valores morales tradicionales. Ambas visiones antagónicas se encuentran en la base de los discursos abolicionistas que lo único que consiguen es convertir en problema moral lo que en verdad es un asunto de política pública, ya que son muchas las mujeres que quedan en situación de desamparo ante la ausencia de regulación legal en sus espacios de trabajo (Villa, 2010).

La CNDH (2011) apoya esta idea al afirmar que son los prejuicios morales los causantes de que aquellas personas dedicadas al trabajo sexual sean señaladas, discriminadas y maltratadas por su oficio. Dicho maltrato toma desde la forma más sutil, como puede ser la burla, hasta la más lastimosa, como puede ser la negación de servicios, violencia física, violación y asesinato.

Si bien en sus inicios el table dance no fue concebido como un espacio de sexo comercial, debido a la transformación que tuvo a raíz de la crisis, actualmente la labor de bailarina erótica se encuentra ligada al fantasma de la prostitución, dado que muchas veces en estos locales se promueve esta actividad, además de permitirse el contacto físico. Todo esto se traduce en una mayor estigmatización hacia estas mujeres, lo cual les entorpece el camino hacia la construcción de una justa ciudadanía, pues permanecen en el anonimato ya que saben que, si decidieran salir de él, son pocas sus probabilidades de ser escuchadas y defendidas.

\section{La ciudadanía}

De acuerdo con Palencia (2004), la estigmatización derivada de la prostitución provoca aislamiento, estancamiento en el oficio y la justificación a quien las explota y maltrata para seguir haciéndolo. Estas mujeres migran generalmente a otras ciudades para trabajar con el objetivo de mantener su labor en secreto. Si bien logran hacer algunas amistades dentro del ambiente, esto no es lo más común ya que se trata de un medio muy competido. Les es difícil colocarse en otros oficios porque, en general, se trata de mujeres sin una formación académica, o experiencia, que les permita acceder a puestos de trabajo en los cuales perciban ingresos similares a los que obtienen bailando. Todas estas condiciones, el aislamiento, la invisibilidad y el estigma, hacen que las mujeres teiboleras no piensen en asociarse o emprender acciones para buscar la superación de su estatus como ciudadanas de segunda, cosa que, a través de la implementación de políticas públicas adecuadas, podría ser posible.

De acuerdo con Sánchez (2008: 94), "la ciudadanía es conocimiento y ejercicio de derechos de la humanidad que exige condiciones y recursos al Estado para vivir con justicia, igualdad y libertad". La ciudadanía se compone de posesión de derechos, pertenencia a una nación y participación social. La autora nos habla de la ciudadana como un sujeto político que cuenta con espacios de expresión, cuestiona la desigualdad y la marginación, se construye desde la sororidad hacia otras mujeres, es consciente de la forma en la cual la variable género impacta su vida, denuncia las violaciones a sus derechos, propone alternativas y participa en su gestión. En palabras de Villa (2010: 165):

El logro de la ciudadanía en nuestras sociedades de mercado abierto, basado en el sistema monetario, se encuentra estrechamente ligado - por no decir que depende- de nuestra 
inserción al mercado de trabajo que, a través de la obtención del salario, nos permite la integración social en una posición y situación social determinadas. En este contexto, el uso del propio cuerpo supone el medio para conseguir un salario o una nómina si se reconoce como un trabajo y la posibilidad de llevar una vida digna como cualquier trabajador potenciando así su capacidad como actor social.

Pecheny (2004), Amuchástegui y Rivas (2008) y Villa (2010) indican que es desde la ciudadanía que se definen los derechos y obligaciones de los individuos. La construcción de la ciudadanía se encuentra marcada por la manera en la cual participamos en la sociedad, y nuestra forma principal de participación es la actividad laboral. $\mathrm{Si}$ bien todas las personas somos iguales ante la ley y tenemos derecho a las mismas oportunidades que los demás, es indudable el hecho de que, en la práctica, muchas personas son tratadas como ciudadanas de segunda, debido a cuestiones de etnia, género, condición socioeconómica o cualquier otra característica ligada a estigmas y prejuicios. Esta ciudadanía de segunda viene dada, pues, por la discriminación, la cual es una relación social de subordinación a través de la que se separa, excluye, segrega, desprecia o y/o agrede a alguien por las "razones" anteriormente mencionadas. Y tal sería el caso de las mujeres bailarinas de table dance, quienes por el hecho de ser mujeres de origen humilde, migrantes, con baja escolaridad y dedicadas a una forma de trabajo sexual, son invisibilizadas y discriminadas por parte de las autoridades y la sociedad en general, convirtiendo el camino a la construcción de ciudadanía en un proceso largo e injustamente complicado.
Pecheny (2004) nos indica que todas las ciudadanías son sexuales pues es imposible separar al ser humano de su sexualidad. Sin embargo, cuando hablamos de ciudadanía sexual, específicamente, nos estamos refiriendo al reconocimiento y ejercicio de los derechos sexuales, reproductivos y a la forma en la que estos se vinculan con los derechos humanos en general.

Al respecto, Amuchástegui y Rivas (2008) puntualizan que, en el caso de las mujeres, el proceso de reconocimiento y ejercicio de los derechos sexuales ha avanzado de manera mucho más lenta que el de los derechos reproductivos, esto porque la reproducción en las mujeres está ligada a la realización máxima del estereotipo de género: la maternidad. Mientras que la sexualidad va ligada a cuestiones como el erotismo y el placer, algo que culturalmente se minimiza en las mujeres o se vincula al fantasma de la "puta" o la "mala mujer". Asimismo, destacan la importancia de vincular la sexualidad a un ejercicio ético de derechos y obligaciones ya que es una dimensión que se actúa en relación con los otros y con sus cuerpos, lo cual vuelve público lo privado debido a que ninguna práctica o actitud que vulnere la integridad de esos otros con los cuales nos relacionamos puede ser considerada legítima.

La ciudadanía es una dimensión legal y política que requiere de leyes y prácticas que garanticen la igualdad y el derecho a participar en los asuntos de la comunidad desde lo individual. Los derechos sexuales tienen que ver con la necesidad de garantizar la salud e integridad sexuales, pues sin esto resulta imposible construir ciudadanía, ya quela sexualidad es parte importante 
de la vida. Esto resulta particularmente urgente cuando hablamos de poblaciones marginadas, es decir, esos conjuntos de individuos que escapan a los dictados de la heteronormatividad, pues son los que se encuentran más vulnerables a los abusos y violaciones a sus derechos. Cuando el estado presenta resistencia a reconocer las demandas y necesidades de estas poblaciones, deja al descubierto la falta de interés por llegar a una inclusión real, en la que todos los individuos, independientemente de sus particularidades, puedan tener acceso a la vivencia de una ciudadanía plena (Ortiz-Ortega, 2008).

La CNDH (2011) y Grande (2011) recomiendan el reconocimiento del trabajo sexual como una labor más y se pronuncia a favor de su regularización y reglamentación, de tal manera que las personas que se dediquen a este oficio puedan denunciar cualquier clase de violación a sus derechos a la que sea sometida. López (2002) sugiere, además, que las bailarinas cuenten con la posibilidad de integrarse al sindicato de artistas, de tal manera que su trabajo sea reconocido como un oficio más dentro del mundo del arte y también se encuentren en posibilidad de pagar impuestos.

Villa (2010), a propósito de la perspectiva abolicionista, nos habla de una persecución por parte del Estado de la mercantilización del cuerpo femenino, que toma como foco a las mujeres dedicadas al trabajo sexual. Esto deriva en una doble violencia dirigida hacia estas mujeres, ya que tales esfuerzos por parte del Estado van motivados, no por un auténtico interés por integrarlas a la vida ciudadana, sino por una doble moral que entiende a las trabajadoras sexuales como el origen de los males provenientes de este oficio, invisibilizando los contextos a los cuales ellas sobreviven cotidianamente y las violencias a las cuales son sometidas tanto en sus espacios de trabajo como fuera de ellos, debido al estigma que su oficio acarrea.

En torno a la ciudadanía sexual, no hay aún un consenso final. Sin embargo, hablar de ciudadanía sexual siempre involucrará el tema de los derechos sexuales, los cuales se pueden situar en las dimensiones de la práctica, de la identidad y de las relaciones. Vinculados con la práctica se identifican el derecho al control y a la seguridad, es decir, el derecho a una vida sexual libre de violencia. Relacionados con la identidad se encuentran el derecho a la autodefinición, la autoexpresión y la autorrealización. Por último, vinculado con las relaciones, está el derecho a consentir (Richardson, 2000).

Si bien los anteriores no son los únicos derechos que la autora menciona, sí son los que en este análisis se relacionan con el trabajo sexual, ya que el reconocimiento al derecho a la vida sexual libre de violencia podría contribuir a mejorar los entornos laborales de las bailarinas, en los que actualmente se lleva a cabo el intercambio comercial erótico sin garantías de seguridad para ellas. El derecho a la autodefinición se relaciona con el derecho a asumir la identidad de trabajadora sexual sin que esto implique convertirse en sujeto desacreditable (Goffman, 1970), así como a no ser definida como persona a partir de su oficio. El derecho a la autoexpresión puede interpretarse como derecho a pronunciarse desde su quehacer como trabajadora sexual, 
cuando esto se haga necesario, y ser escuchada a partir de esa posición y no a pesar de ella (Parrini, Amuchástegui y Garibi, 2014). El derecho a la autorrealización será aquel que garantice igualdad de condiciones económicas y legales, desde las cuales ejercer el oficio de bailarina. Y, finalmente, el derecho a consentir, que puede vincularse con la posibilidad de decir que "sí" al trabajo sexual —en condiciones de ejercicio de los derechos anteriormente mencionados-, sin que esto sea considerado un trabajo al margen de la ley, susceptible de ser sancionado o perseguido, pues cuando esta labor se sataniza, el foco de la persecución siempre son ellas, nunca los clientes que consumen sus servicios.

A propósito de la ciudadanía sexual, Plummer (2003) plantea algunas preguntas generadoras, que tienen que ver con la forma en la que hacemos intimidades, relaciones, emociones, cuerpos, identidades y sexualidades. También se pregunta acerca de nuestras formas particulares de ver el mundo y la forma en la cual llegamos a ellas; la construcción de nuestras intimidades; la manera en la que las moralidades permean los discursos e historias que habitamos; las estrategias a seguir para escuchar a aquellos que hablan desde posiciones distintas y la forma en la que la utopía se conecta con las desigualdades vigentes. El autor habla de la ciudadanía sexual como una meta-narrativa en la que tengan cabida todas las historias posibles, no con el objetivo de construir una verdad única y universal, sino con el ánimo de aprender a dialogar y aprender de la forma en la que los otros se enfrentan a los conflictos. Complementando la idea, Richardson (2015) plantea un cuestionamiento en torno a las otras formas de ciudadanía sexual que pueden surgir, a partir de contextos geo-políticamente diversos —cultural, social, económicos.

\section{Las subjetividades}

Amuchástegui y Rivas (2008: 114) hablan de la importancia de la subjetividad cuando hacen referencia al hecho de que el proceso de ciudadanización requiere de la subjetivación, es decir, de individuos que desarrollen y mantengan "un sentido del derecho a tener derechos para sí y para los demás miembros de la colectividad". Dichos procesos subjetivos son descritos por las autoras como prácticas tanto individuales como colectivas de apropiación de los derechos, así como acciones de autorización de sí con respecto al cuerpo y sus placeres, siempre en el contexto de la justicia social ya que la existencia de los derechos expresa el aspecto más formal de la ciudadanía.

Cuando se han dado los procesos subjetivos mediante los cuales los individuos reconocen la posibilidad de disponer de sus cuerpos, su sexualidad y su reproducción, necesariamente viene la exigencia hacia el Estado para que se garanticen las condiciones sociales, económicas e institucionales favorables para el ejercicio pleno de su ciudadanía (Amuchástegui y Rivas, 2004).

La persona estigmatizada no es considerada como totalmente humana y es por esto que se le aplican diversos tipos de discriminación (Goffman, 1970; Butler, 2006). Cuando luchamos por nuestros derechos, estamos luchando por ser concebidos como personas, Las mujeres deben iniciar la lucha buscando su reconocimiento como 
personas, ya que nunca han sido completamente incorporadas en lo humano (Butler, 2006). Y si a esto sumamos un oficio que las coloca en posición de sujeto desacreditable (Goffman, 1970), la búsqueda de reconocimiento como ciudadanas de pleno derecho se hace aún más compleja.

Aquí resulta indispensable subrayar que, cuando nos referimos al tema de la construcción de subjetividades y el reconocimiento de las mujeres como personas, estamos hablando en plural de las mujeres. No de "la mujer" como ese elemento estático que ocupa la posición opuesta a la masculina dentro de un sistema ideológico binario, sino de las mujeres como experiencias diversas encarnadas. Para esto, resulta indispensable atender a las diferencias que se dan, no entre hombres y mujeres, sino dentro de las mujeres (De Lauretis, 1989; Scott, 1992) y desde sus experiencias.

La experiencia individual es el resultado de una constante tensión entre las presiones externas y las resistencias internas, y se relaciona con la subjetividad en construcción, el cuerpo y la actividad política (De Lauretis, 1989). La problemática micropolítica no está situada en el nivel de la representación, sino en el nivel de producción de subjetividad (Guattari y Rolnik, 2006).

Somos resultado de una producción en masa. La subjetividad está fabricada y modelada en el registro de lo social. Un individuo siempre existe en cuanto terminal: el individuo consume subjetividad, consume sistemas de representación, de sensibilidad que ya están prefabricadas. Y la forma en la que nos relacionamos con esta subjetividad oscila entre dos extremos: uno en el que encontramos una relación de alienación y opresión y otro en el que encontramos una relación de expresión y de creación, en la que el individuo se reapropia de los elementos que componen la subjetividad en un proceso de singularización (Guattari y Rolnik, 2006).

Este juego entre la alienación/opresión y el uso creativo de las posibilidades de resistencia, es posible verlo, en escena, en el teatro del table dance. Las bailarinas disocian, se separan de su papel, comercializan el cuerpo dramatizando, actuando la parte que les toca. Ponen esta coreografía erótica al servicio de su supervivencia, en un contexto social que limita la participación económica de las mujeres. Pero, y tal vez ahí se encuentra el foco de su resistencia, no se lo toman demasiado en serio. Pueden ser víctimas o putas “de a de veras", pero todo aquello no es más que un performance a través del cual convencen al cliente para vender el producto. Aquí podemos identificar una dimensión, a la que llamaré "pasiva", de la tarea de resistencia, que tendría que ver con la disociación que hacen entre su papel como bailarinas y su identidad como novias, esposas, madres e hijas. Y es posible también identificar una dimensión a la que llamaré "activa" que se desprende de esta performatividad que se despliega al momento de desarrollar y dramatizar el papel de teibolera.

Aquí podría encajar el concepto de la contra-sexualidad propuesto por Preciado (2002), ya que es una posición desde la cual se propone una lucha en contra de la producción disciplinaria de sexualidades, identidades y subjetividades, no en forma de un enfrentamiento directo, sino de 
la aplicación de la contra-productividad como tecnología al servicio de la resistencia, ubicada fuera de las dicotomías de los géneros, los sexos, e identificando a la identidad como tecnología al servicio del poder. Un poder que se aplica sobre individuos libres, que es la acción sobre las acciones de otros, que se encuentra sólo en las relaciones sociales, en movimiento, y que, inevitablemente, genera estrategias de resistencia (Foucault, 1988).

Por otro lado, es importante recordar que ese "registro de lo social" desde el cual se forma la subjetividad, se encuentra permeado por dinámicas de poder. Cuando hablamos de género, hablamos de poder, de identidades atravesadas por una valoración jerarquizada (San Miguel, 2015). Y cuando hablamos de clase, oficio y condición migratoria, también.

Al actuar su papel, las mujeres bailarinas hacen explícito el intercambio comercial que muchas veces encubre el sistema de relaciones heterosexuales en el patriarcado, en el cual las mujeres se entregan en calidad de sujetas-para otro, a cambio de protección, dinero o estatus. Lo hacen explícito con su trabajo y, en el proceso, hacen uso de la disociación entre sexualidad y emociones, tan característica de "lo masculino" en nuestra sociedad patriarcal. El cliente no es el objetivo, aunque la actuación gire en torno suyo. El cliente es el medio, el objetivo es el intercambio económico. Ella niega el vínculo emocional y con eso mantiene parte esencial de su subjetividad al margen; no existe promesa de monogamia y el teatro del amor dura lo que le dure el dinero al hombre en turno. Ella usa conscientemente su sexualidad, disocia, miente y cobra por ello. Y cuando todo acaba, devuelve el cuerpo a su realidad doméstica.

El trabajo sexual tendría que ser una actividad susceptible de ser permeada por derechos, obligaciones y procedimientos sistemáticos, regulares y en apego a la ley.

Como bien plantean Amuchástegui y Rivas (2004), desde la división sexual del trabajo, a las mujeres se nos ha visto siempre como instrumentos, como objetos al servicio del bienestar del otro, por eso es difícil que busquemos la salud y mucho menos el placer para nuestros propios cuerpos. Y no solo eso, sino que, en casos de extrema pobreza, usamos el cuerpo como medio de trabajo.

A veces se considera que la trabajadora sexual traiciona los ideales del feminismo pues el trabajo sexual convierte en un objeto a la mujer, siendo que, lo que realmente la coloca en posición de objeto es mirarla como una víctima indefensa incapaz de emitir opiniones en torno a su propia situación y dependiendo por esto de opiniones expertas que, en muchos casos, no han vivido en carne propia la experiencia de ejercer el trabajo sexual (Briz y Garaizabal, 2007).

De acuerdo con Foucault (1988) hay dos formas de entender al sujeto, en este caso a las bailarinas de table dance: como sujetas a la dominación de otros que se benefician de las condiciones laborales arbitrarias en las que trabajan, y sujetas - más bien vinculadas - a su propia identidad, a su propio conocimiento y conciencia de sí. Las mujeres bailarinas reconstruyen su identidad negociando con el estigma introyectado, actuando y disociándose de 
su papel, aferrándose a otros roles más vinculados con sus emociones.

Retomo lo dicho por Briz y Garaizabal (2007), quienes hablan de la importancia de combatir el estigma, el cual se erige como el mayor impedimento en el camino a la construcción de ciudadanía por parte de las trabajadoras sexuales. La discriminación las mantiene aisladas, calladas e invisibles, lo cual impide que se denuncien violaciones, exijan justicias y que sean partícipes en la planeación e implementación de políticas encaminadas a garantizar su seguridad y el pleno ejercicio de sus derechos. López (2008), por su parte, apoya lo anterior y destaca el hecho de la competencia y deslealtad -derivados del mismo estigma - que existe entre compañeras de trabajo, lo cual impide que se creen los vínculos y complicidades sociales necesarias para vivirse como comunidad y tomar fuerza como colectivo.

\section{CONCLUSIONES}

Las ciudadanías están relacionadas con la forma en la que los individuos participamos en la sociedad. La forma principal de participación es el trabajo, nuestra actividad económica. La actividad del table dance constituye, junto con muchas otras actividades laborales no estigmatizadas, una forma de explotación de las trabajadoras y una práctica que reproduce los valores patriarcales de uso del cuerpo de las mujeres. Involucra el ejercicio de una ciudadanía sexual, pues la labor que se realiza cabe dentro de la categoría de trabajo sexual, al ser un intercambio de lo erótico con fines comerciales.

Para entender las posibilidades de ciudadanía sexual a partir de este oficio, es necesario hablar en términos de derechos sexuales y, después, hablar de la forma en la que la subjetividad del individuo se construye como más o menos favorecedora de un reconocimiento de sí mismo como persona, primero, y como persona susceptible de ejercer derechos, después.

Las relaciones entre las bailarinas se encuentran permeadas por la necesidad de competir: el trato que se da entre ellas suele ser indiferente, sin embargo, en los camerinos es común escuchar anécdotas de enfrentamientos verbales entre ellas o de rivalidades que se han ido construyendo en la convivencia. La unidad entre mujeres es un elemento que sería deseable en el proceso de construir ciudadanía, ya que desde la unión entre individuos que se enfrentan a condiciones similares, se puede dar un pronunciamiento a favor de la visibilización de las opresiones padecidas, de los derechos no reconocidos.

Con respecto a las condiciones laborales arbitrarias, que son condiciones estructurales opresoras, éstas tienen que ver con el hecho de que no existe contrato de trabajo, estabilidad laboral ni prestaciones de ninguna clase, lo cual permite la existencia de dinámicas laborales basadas en la explotación, como lo son: el hecho de que el sueldo del resto del personal dependa de la bailarina; el pago de sueldo condicionado al logro de una cierta meta de venta de copas y/o privados y los descuentos de sueldo que se hacen por "salida" con el cliente.

El estigma, por su parte, provoca que las bailarinas, en su mayoría, se conviertan en migrantes para poder ejercer su oficio, debido a la necesidad de mantener esta actividad oculta de su círculo cercano. Esto acarrea aislamiento y anonimato y la red de 
mentiras que la mujer se ve forzada a mantener para no ser descubierta y rechazada. Asimismo, el estigma conlleva la descalificación e invisibilización por parte de autoridades y servidores públicos que se niegan a tomar en serio y dar seguimiento a las demandas de las bailarinas. Aquí cabría hacer un paréntesis para mencionar el caso de la Ciudad de México y el Estado de México, entidades en las que, desde el 2013, se han dado los cierres de numerosos establecimientos de table dance durante operativos cuyo objetivo fue la liberación de víctimas de trata. Esto motivó protestas en las que las bailarinas, junto con meseros y patrones, solicitaban a las autoridades la reapertura de sus lugares de trabajo. Esto implica el ejercicio del derecho a la autoexpresión, a pronunciarse desde el oficio a través del cual se participa en la sociedad.

El derecho al control y a la seguridad sobre el propio cuerpo no es reconocido ni ejercido, ya que el trabajo de teibolera, está vinculado a la presencia no controlada de drogas ilegales dentro del lugar de trabajo; los robos a los que se exponen por no contar con un espacio verdaderamente privado para resguardar sus pertenencias mientras realizan su trabajo; los intercambios sexuales que se dan en los privados en los cuales se pone en riesgo su salud; las "salidas", en las cuales la bailarina se expone a negociar intercambios sexuales sin garantías de seguridad por parte del cliente; el hecho de que el patrón o dueño del negocio rara vez se identifique con las bailarinas — pues quien recluta y coordina generalmente es el capitán de meseros o el DJ- y la presión constante para realizarse procedimientos estéticos invasivos, con tal de seguir siendo competitiva en el medio.
La forma en la que estas mujeres se relacionan con su papel como bailarinas habla de un proceso de resistencia situado en la identidad. Sus discursos giran en torno a las siguientes ideas: putas son las que lo disfrutan, las que lo hacen o lo harían gratis. Ellas lo hacen por necesidad. Preferirían no hacerlo, pero tienen que sostener económicamente a sus familias y no abundan los trabajos con sueldos similares a los de teibolera. Luego entonces ellas son madres, hijas, esposas, novias — se reconocen como tales - que se ven obligadas a actuar el papel de trabajadoras sexuales por unas horas, por una situación que escapa de su control. Son novias fieles, porque si el contacto sexual se da en el contexto laboral entonces "no cuenta" como infidelidad. Son madres e hijas responsables, porque el dinero que ganan es para el sustento de sus seres queridos. Y son estudiantes comprometidas que buscan en el trabajo sexual el pago por esos estudios que les llevarán a convertirse en profesionistas. El table dance es un papel que representan, pero que, ciertamente, no hay que tomarse demasiado en serio. Poner distancia entre "quién soy" y a "qué me dedico", para no permitir que el estigma lastime demasiado.

Las mujeres se esconden para trabajar en el baile erótico. No bailan en su ciudad natal y ocultan su oficio a toda persona ajena a su contexto laboral. Ellas saben que su empleo es informal, y el hecho de no contar con contrato, prestaciones y condiciones laborales estables, lo viven como una consecuencia natural de dedicarse a un oficio que se desarrolla en los márgenes de la legalidad. Reconocen injusticia y arbitrariedad en el trato recibido por parte de algunos empleadores y compañeros de trabajo, pero lo consideran como una consecuencia "natural" de 
dedicarse al table dance. En las pocas ocasiones en las cuales me atreví a quejarme de las condiciones laborales, los comentarios recibidos por parte de mis compañeras de trabajo fueron los siguientes: "En este negocio, así son” (a propósito de la actitud agresiva de algunos meseros); "Hay que aprovechar, porque no todos son buena onda" (refiriéndose a uno de los patrones, que en ocasiones nos compraba comida y se mostraba amable con nosotras); "Es que aquí, así es" (hablando de las sanciones y los descuentos arbitrarios). Y otros parecidos, que denotan un entendimiento del mundo del table dance como un espacio en el que siempre se está a merced de lo que el jefe en turno - capitán de meseros, "mami” o dueño- decidan.

Cuando me encontraba laborando en el segundo establecimiento en el que estuve, me enteré - por unas bailarinas conocidas - que el primer lugar en el que había trabajado estaba clausurado. Me contaron que durante varias horas, mantuvieron encerrado a todo el personal del table dance, mientras se realizaban revisiones. Finalmente, dejaron salir a todos pero el lugar quedó clausurado. Nunca más volvió a abrir sus puertas como table dance. Fue remodelado y al día de hoy sigue funcionando, pero como bar gay. Las bailarinas miran a las autoridades más como una amenaza que como aliados o como recurso. Temen que les “caigan" en su centro de trabajo, porque eso implica revisiones a sus pertenencias, posibles aprehensiones y el cierre - temporal o permanente - de su fuente de empleo. Los derechos sexuales y la ciudadanía son ideas lejanas.

El cuerpo de la bailarina es su herramienta de trabajo. Zapatos de plataforma de alturas que atentan contra el equilibrio; telas ajustadas y brillantes que cubren lo esencial y esa actitud alegre y despreocupada que invita al potencial cliente a unirse a la fiesta y, a los que ya están, a quedarse en ella y seguir comprando fantasías a precio de copa. Ése es el papel que se asume, y éste se dramatiza constantemente, es decir, se acentúa por medio de movimientos, actitudes, gestos, carcajadas, palabras, y de la voz, que sube escandalosa o baja seductora, según lo requiera el momento.

En uno de esos lugares, se hacía lesbian show, ${ }^{2}$ pasada la medianoche. Posterior a uno de esos shows, un cliente le preguntó a una de las chicas si en realidad era lesbiana o bisexual, a lo que ella respondió: "No, es sólo por el show." Es la representación de un papel y su respectiva dramatización, nada más. Lo que importa en el contexto laboral es mostrarse y convencer; lo que importa afuera es ocultar y simular.

Una de las bailarinas de más edad — pasados los cuarenta - se jactaba de no tener necesidad de hacer privados, porque sabía sacar propinas de los clientes "sin meter cuerpo", es decir, sin dejarse tocar tanto como las chicas más jóvenes y menos experimentadas. Tal vez lo que vende no es sólo el físico como superficie susceptible de aceptar tocamientos, sino también la actitud que recrea la fantasía de la mujer erótica siempre alegre y dispuesta.

El "baile exótico" o table dance es una forma de trabajo sexual como existen otras, en las cuales

2 Lesbian show es un espectáculo en el que, por un lapso de media hora aproximadamente, dos bailarinas suben al escenario y simulan tener relaciones sexuales. Para esto, es común el uso de crema de afeitar, leche condensada o crema chantilly. 
se presentan riesgos no solo para la salud sexual de quien lo ejerce sino también para su salud mental y social. No se trata de un problema de índole moral sino de derechos humanos y de acceso a condiciones laborales dignas que permitan a la trabajadora el ejercicio de derechos que tienen que ver con la regulación de sus condiciones laborales, de tal manera que la posibilidad de explotación sea eliminada o reducida al mínimo; el trabajo en entornos seguros; la vida libre de estigmas; el no ser nombrada ni definida a partir de su oficio; el poder pronunciarse a partir de este oficio cuando esto se considere necesario $\mathrm{y}$, en resumen, poder vivir del table dance sin que esto comprometa el reconocimiento a esos derechos que se desprenden de su calidad de ciudadana, independientemente de la naturaleza del trabajo a través del cual se establezca su participación social. əo 


\section{BIBLIOGRAFÍA}

Amuchástegui, Ana y Marta Rivas (2004), "Los procesos de apropiación subjetiva de los derechos sexuales: notas para su discusión”, en Estudios Demográficos y Urbanos, vol. 19, núm. 3, pp. 543-597.

Amuchástegui, Ana y Marta Rivas (2008), “Construcción subjetiva de ciudadanía sexual en México: género, heteronormatividad y ética”, en Ivonne Szasz y Guadalupe Salas (coords.), Sexualidad, Derechos Humanos y Ciudadanía. Diálogos sobre un proyecto en construcción. México, El Colegio de México.

Barrero Díaz, Gloria Patricia (2004), "Bailarinas exóticas, striptease e inmigración en Canadá”, en Colombiana Internacional, núm. 59, pp. 142-158, consultado el 6 de febrero de 2013, URL: http:// www.redalyc.org/articulo.oa?id=81205907

Briz, Mamen y Cristina Garaizabal (coords.) (2007), La prostitución a debate. Por los derechos de las prostitutas. Madrid, Ediciones Talasa.

Butler, Judith (2006), Deshacer el género. Barcelona, Paidós.

Castañeda, Martha Patricia (2006), “La antropología feminista hoy: algunos énfasis claves”, en Revista Mexicana de Ciencias Políticas y Sociales, vol. 48, núm. 197, pp. 35-7, consultado el 20 de octubre de 2015, URL: http://www.redalyc.org/articulo.oa?id=42119704

Castañeda, Martha Patricia (2012), “Etnografía feminista”, en Norma Blazquez, Fátima Flores y Maribel Ríos (coords.), Investigación feminista. Epistemología, metodología y representaciones sociales. México, UNAM/CEIICH.

Comisión Nacional de los Derechos Humanos (CNDH) (2011), El VIH, el SIDA y los derechos humanos: el caso de las y los trabajadores sexuales. México, CNDH.

De Lauretis, Teresa (1989), Technologies of gender. Essays on theory, film and fiction. London, Mcmillan Press.

De Lauretis, Teresa (1993), “Sujetos excéntricos: la teoría feminista y la conciencia histórica”, en María Cangiano y Lindsay DuBois (comps.), De mujer a género, teoría, interpretación y práctica 
feministas en las ciencias sociales. Buenos Aires, Centro Editor de América Latina.

Foucault, Michel (1988), “El sujeto y el poder”, en Revista Mexicana de Sociología, vol. 50, núm. 3, pp. 3-20.

Goffman, Erving (1970), Estigma. La identidad deteriorada. Buenos Aires, Amorrortu.

Goffman, Erving (1971 [1959]), La presentación de la persona en la vida cotidiana. Buenos Aires, Amorrortu.

Grande, Mirtha (2011), “Trabajo sexual y derechos humanos”, en Carlos Cáceres, María Esther Mogollón, Griselda Peréz-Luna y Fernando Olivos (eds.), Sexualidad, ciudadanía y derechos humanos en América Latina. Un quinquenio de aportes regionales al debate y la reflexión. Lima, IESSDEH/UPCH.

Guattari, Félix y Suely Rolnik (2006), Micropolítica. Cartografias del deseo. Madrid, Traficantes de sueños. URL: http://esferapublica.org/cartografiasdeldeseo.pdf

Haraway, Donna (1988), "Situated knowledges: The science question in feminism and the privilege of partial perspective", en Feminist studies, vol. 14, núm. 3, pp. 575-599. URL: http://www.staff.amu. edu.pl/ ewa/Haraway,\%20Situated\%20Knowledges.pdf

Jeffreys, Sheila (2011), La industria de la vagina. La economía política de la comercialización global del sexo. Buenos Aires, Paidós.

Justo, Carolina y Santiago Morcillo (2008), "Le ofrezco señor, este cuerpo sin alma. Corporeización y subjetividad de mujeres en prostitución”. IX Congreso Argentino de Antropología Social. Facultad de Humanidades y Ciencias Sociales. Universidad Nacional de Misiones, Posadas. URL: https:// www.aacademica.org/000-080/226.pdf

Kawulich, Barbara (2005), "La observación participante como método de recolección de datos", en Forum: Qualitative Sozialforschung/Forum: Qualitative Social Research, vol. 6, núm. 2, consultado el 12 de noviembre de 2015, URL: http://www.qualitative-research.net/index.php/fqs/article/view/466/998

Lagarde, Marcela (2005), Los cautiverios de las mujeres: madresposas, monjas, putas, presas y locas. México, UNAM. 
Lamas, Marta (1993), "El fulgor de la noche: algunos aspectos de la prostitución callejera en la ciudad de México", en Revista Debate Feminista, vol. 8, año. 4, pp. 103-134.

Loaiza, Martha, Lina Moreno y Eliana Zuluaga (2007), “Apartar la mente del cuerpo: un acercamiento a los pensamientos y sentimientos de las estudiantes universitarias trabajadoras sexuales", en Revista de la Facultad Nacional de Salud Pública, vol. 25, núm. 2, pp. 95-99, consultado el 8 de febrero de 2013, URL: http://www.redalyc.org/articulo.oa?id=12025212

López Villagrán, Gilberto (2002), Espectáculo sexual, mercado y políticas públicas. La consulta pública, el Lobohombo y la sobreoferta sexual en España. México, INMUJERES.

López Villagrán, Gilberto (2008), "Estigma negativo como obstáculo para la construcción de ciudadanía: el colectivo de bailarinas que ejercen el table dance", en Silvia Bolos (coord.), Mujeres y espacio público: Construcción y ejercicio de la ciudadanía. México, Universidad Iberoamericana.

Olvera Maldonado, Briseida Gwendoline (2006), "Bailando noche tras noche alrededor de un tubo: algunas características de las condiciones de trabajo en los table dance de la Zona Metropolitana de Guadalajara”, en Revista de Estudios de Género, La Ventana, núm. 24, pp. 320-342, Universidad de Guadalajara.

Ortiz-Ortega, Adriana (2008), "Debates actuales en torno a los derechos sexuales y la ciudadanía sexual. Precarias negociaciones sobre los derechos sexuales desde los movimientos sociales", en Ivonne Szasz y Guadalupe Salas (coords.), Sexualidad, Derechos Humanos y Ciudadanía. Diálogos sobre un proyecto en construcción. México, El Colegio de México, pp. 375-432.

Pachajoa, Alejandro y Jhonny Figueroa (2008), “¿Es la prostitución un trabajo?”, en Revista Tesis Psicológica, núm. 3, pp. 54-69, consultado el día 10 de febrero de 2013, URL: http://www.redalyc. org/articulo.oa? id=139012667007

Palencia, Rosa María (2004), "Excluidas y marginales: un alegato a favor de los derechos y la libertad de las mujeres que transgreden la norma patriarcal", en Revista de Estudios de Género, La Ventana, núm. 20, pp. 390-396, consultado el día 4 de Febrero de 2013, URL: http://www.redalyc.org/ pdf/884/88402018.pdf

Parrini, Rodrigo, Ana Amuchástegui y Cecilia Garibi (2014), “Límites, excedentes y placeres: Prácticas 
y discursos en torno al trabajo sexual en una zona rural de México", en Revista Latinoamericana, núm. 16, pp. 153-172, consultado el 16 de octubre de 2015, URL: http://www.e-publicacoes.uerj. br/index.php/SexualidadSaludySociedad/article/view/8173

Pecheny, Mario (2004), "Lógicas de acción colectiva de los movimientos por los derechos sexuales: un análisis con aires abstractos de experiencias bien concretas", en Carlos Cáceres, Timothy Frasca, Mario Pecheny y Veriano Terto (eds.), Ciudadanía sexual en América Latina: abriendo el debate. Lima, Facultad de Salud Pública y Administración, Universidad Peruana Cayetano Heredia.

Pecheny, Mario (2014), "Estigma y discriminación en los servicios de salud a las mujeres trabajadoras sexuales en América Latina y el Caribe”, en Gazeta de Antropología, núm. 30 (3), consultado el 16 de octubre de 2015, URL: http://www.gazeta-antropologia.es/?p=4622

Plummer, Ken (2003), Intimate citizenship. Private decisions and public dialogues. Seattle Washington, University of Washington Press.

Preciado, Beatriz (2002), Manifiesto contra-sexual: Prácticas subversivas de identidad sexual. Madrid, Opera Prima. URL: https://www.sertao.ufg.br/up/16/o/Beatriz_Preciado_-_Manifiesto_contrasexual_(2002).pdf?1373809656

Richardson, Diane (2000), “Constructing sexual citizenship: theorizing sexual rights", en Critical Social Policy, vol. 20, núm. 1, pp. 105-135, consultado el 12 de febrero de 2016, URL: http://is.muni.cz/ el/1423/jaro2010/GEN141/um/Richardson_sexual_citizenship.pdf

Richardson, Diane (2015), "Rethinking Sexual Citizenship", en Sociology, pp.1-17, consultado el 12 de febrero de 2016, doi: 10.1177/0038038515609024.

Sánchez Olvera, Alma (2008), "El cuerpo: espacio de construcción y ejercicio de ciudadanía desde los derechos sexuales y reproductivos", en Silvia Bolos (coord.), Mujeres y espacio público: Construcción y ejercicio de la ciudadanía. México, Universidad Iberoamericana.

San Miguel, Maite (2015), "Efectos en las subjetividades contemporáneas de la desigualdad y de las relaciones de poder entre los modelos de masculinidad y feminidad", en Almudena Hernando (ed.), Mujeres, hombres, poder. Subjetividades en conflicto. Madrid, Traficantes de sueños, pp.151-174. 
Scott, Joan (1992), "Igualdad versus diferencia: los usos de la teoría postestructuralista", en Debate feminista, vol. 5, año. 3, pp. 85-104.

Fecha de recepción: 21 de octubre de 2015

Fecha de aceptación: 7 de marzo de 2016

\section{ACERCA DE LA AUTORA}

\section{CLAUDIA SALINAS BOLDO}

(claudia_salinas_boldo@hotmail.com)

Es maestra en antropología social por la Universidad Autónoma de Yucatán y egresada del doctorado en antropología social de la Universidad Nacional Autónoma de México. Actualmente se desempeña como investigadora titular del Instituto de Investigación y Desarrollo Educativo de la Universidad de Baja California. Entre sus áreas de interés destacan género, educación, el estudio de mujeres en prisión y sexualidad. Es autora de "Las cárceles de mujeres en México, espacios de opresión patriarcal", en Revista de Ciencias Sociales de la Universidad Iberoamericana, 9 (117) (2014). [http://www.ibero.mx/ iberoforum/17/pdf/ESPANOL/1_CLAUDIA_SALINAS_NOTAS_PARA_ELDEBATE_NO17.pdf] y coautora de "Violencia temprana: percepción de los celos y el control como formas de abuso emocional en mujeres estudiantes universitarias", en Aurelia Flores, Adelina Espejel, Leonor Rocha y Carmen Flores (coords.), Género y juventud. Rutas para la investigación (Universidad Autónoma de Tlaxcala, 2013). 